\title{
INTERFACES ATUAIS ENTRE A E-JUSTIÇA E A Q-JUSTIÇA NO BRASIL
}

\author{
Cesar Antonio Serbena
}

\begin{abstract}
RESUMO
Atualmente o sistema judicial brasileiro vive um periodo de rápida transformação. Os cartórios judiciais, os tribunais estaduais, federais e tribunais superiores informatizaram ou parcialmente ou integralmente todo o trâmite processual. Com a informatização da gestão dos processos judiciais, dos cartórios e dos tribunais, praticamente o escritório do advogado e das partes do processo, como o Ministério Público, fica incorporado ao processo. Para que um advogado peticione e atue no processo, ele não precisa mais deslocar-se até o fórum, basta acessar um terminal de computador. O chefe de secretaria também tende a desaparecer, pois com a eliminação do processo físico, toda a gestão processual passa a ser gerida por um sistema. Esta é a chamada Justiça eletrônica ou E-Justiça. De forma concomitante com esse processo de informatização, houve a implantação de um sistema de coleta de dados e de análise estatística do Poder Judiciário, assim como um sistema de avaliação de sua performance, através de índices especificos. Este sistema pode ser denominado Justiça quantitativa ou Q-Justiça. No presente trabalho, analisamos as interfaces atuais entre a E-Justiça e a Q-Justiça, ou seja, descrevemos os principais sistemas de coleta de dados do Poder Judiciário brasileiro, indicamos algumas observações de ordem metodológica relativa à disponibilização pública dos dados e à pesquisa estatística com dados judiciais, e apontamos as perspectivas futuras da métrica judicial com relação às novas tecnologias computacionais, como a mineração de dados e computação em nuvem.
\end{abstract}

PALAVRAS-CHAVE: Conselho Nacional de Justiça; justiça eletrônica; métrica judicial; data-mining; cloud-computing.

\section{INTRODUÇÃO ${ }^{1}$}

Neste início da segunda década do século XXI, o poder Judiciário no Brasil é influenciado pelo avanço tecnológico e, principalmente, computacional: estamos no início da transformação do processo físico, analógico, em um processo eletrônico e digital, fortemente operacionalizado pela internet. $\mathrm{Na}$ vanguarda desse processo, no Brasil, estão os tribunais superiores, principalmente o Supremo Tribunal Federal (STF) e o Supremo Tribunal de Justiça (STJ), que já converteram integralmente sua tramitação processual para o formato eletrônico. Dentro do poder Judiciário, também o Conselho Nacional de Justiça (CNJ), vem induzindo e implementando políticas de reforma dos tribunais estaduais e federais, para que estes sigam o exemplo dos tribunais superiores e promovam medidas de reforma da tramitação processual rumo ao processo eletrônico, rumo à E-Justiça ou Justiça eletrônica.

Em paralelo ao processo de conversão do processo judicial para o formato eletrônico, outra grande reforma do aparato judicial entrou em operação no Brasil: tratase da implementação de um sistema de coleta e análise

\footnotetext{
1 Gostaria de agradecer aos pareceristas anônimos da Revista de Sociologia e Politica por suas sugestões para este artigo, à CAPES e ao CNJ - Conselho Nacional de Justiça, financiadores conjuntos desta pesquisa pelo programa CNJ Acadêmico"..
}

estatística dos dados dos tribunais. Por meio de várias medidas legais, está em processo de implantação uma cultura para a abertura das informações, de modo que, por meio da análise dos dados do poder Judiciário mediante certos índices, a sociedade e os órgãos de gestão estratégica do sistema judicial possam identificar problemas e planejar a sua solução. Em complemento à E-Justiça, temos atualmente também um sistema de métrica judicial ou justiça quantitativa, a Q-Justiça.

A análise do desempenho das cortes e tribunais no Brasil têm causado certa surpresa, quando não sentimentos de rejeição. Muitas causas podem ser apontadas para esse impacto negativo, porém, a princípio, podemos apontar duas principais: $(i)$ o desconhecimento dos dados relativos ao sistema judicial. Nas duas décadas posteriores à Constituição Federal de 1988, praticamente não havia um sistema de coleta de dados e informações relativas ao poder Judiciário no Brasil. Havia informações isoladas e fragmentadas, mas sem a elaboração dos índices não era possível radiografar o sistema judicial em termos estatísticos. A partir da criação do Conselho Nacional de Justiça e da implementação de suas políticas, gradativamente os dados relativos ao poder Judiciário começaram a aparecer publicamente, causando as mais variadas reações. $\mathrm{O}$ exemplo mais conhecido foi o impacto provocado pela série de pesquisas “Os 100 
maiores litigantes", na qual o governo federal e os bancos apareceram como os maiores demandantes judiciais do Brasil, e continuam na mesma posição segundo o último relatório, com os dados de 2011. (ii) $\mathrm{O}$ desconhecimento dos sistemas de avaliação e controle das modernas democracias ocidentais. Em continuação ao processo anterior, o Conselho Nacional de Justiça firmou-se também como órgão de implementação de políticas estratégicas de modernização do poder Judiciário. Nesse processo de modernização, foram criados órgãos e equipes internas ao $\mathrm{CNJ}$, com a finalidade de produzir conhecimentos e técnicas específicas que viabilizassem os meios para a implementação das novas políticas de gestão e controle. Conseqüentemente, buscou-se nos sistemas judiciais de outros países, como os Estados Unidos, o México e a Conselho da Europa, elementos e experiências que pudessem ser também implementadas no Brasil. De certo modo, ainda não tínhamos presente no Brasil a cultura de coleta de dados, de medição, avaliação e controle do sistema judicial.

A análise dos sistemas judiciais e seu desempelho não é algo novo fora do Brasil. Os Estados Unidos e a Conselho da Europa produzem constantemente relatórios estatísticos para a análise do seu sistema, bem como para sua avaliação ${ }^{2}$.

No presente trabalho, descrevemos os principais sistemas de coleta de dados do poder Judiciário brasileiro, indicamos algumas observações de ordem metodológica, relativas à diponibilização pública dos dados e à pesquisa estatística com dados judiciais, e apontamos as perspectivas futuras da métrica judicial com relação às novas tecnologias computacionais.

\section{O SITUAÇÃO ATUALDAQ-JUSTIÇANO BRASIL}

Atualmente, dentro do âmbito do CNJ e do STF, os principais sistemas de coleta de dados do Poder Judiciário em operação são3: "Justiça em Números", "Justiça Aberta", "Resolução n. 88/2009", "Resolução n. 102/2009", "Indicadores estratégicos do Poder Judiciário" e "O Supremo em Números".

\footnotetext{
2 O leitor interessado em maiores detalhes dos relatórios da Conselho da Europa e dos Estados Unidos poderá consultar, respectivamente, o sítio do European Commission for the Efficiency of Justice (cf. EUROPEAN COMMISSION FOR THE EFFICIENCY OF JUSTICE, 2010) e o relatório do National Center for State Courts (cf. NATIONAL CENTER FOR STATE COURTS, 2010).
}

3 Para a exposição do item um deste artigo, baseamo-nos na pesquisa do CNJ, "Estudos sobre os sistemas de coleta de dados" (cf. CONSELHO NACIONAL DE JUSTIÇA, 2010).

\section{II.1. O sistema “Justiça em Números" do CNJ}

O sistema do CNJ disponibilizou informações estatísticas sobre o poder Judiciário pela primeira vez nos anos de 2003 e 2004, sendo desenvolvido a partir do sistema anterior, o Banco Nacional de Dados do Poder Judiciário (BNDPJ). Em 2005 foi criado o Sistema de Estatística do Poder Judiciário (SIESPJ), por meio da Resolução n. 4, de 16 de agosto de 2005, da Presidência do CNJ. A Resolução n. 15, de 20 de abril de 2006, regulamentou o sistema e estabeleceu seus índices e fórmulas. A Resolução $\mathrm{n} .15$ foi revogada e a base normativa do sistema atualmente está estabelecida pela Resolução n. 76, de 12 de maio de 2009.

Basicamente, o SIESPJ possui os indicadores estatísticos básicos, divididos nas seguintes categorias: I-Insumos, dotações e graus de utilização: a) Receitas e despesas; b) Estrutura. II - Litigiosidade: a) Carga de trabalho; b) Taxa de congestionamento; c) Recorribilidade e reforma de decisões. III - Acesso à Justiça. IV - Perfil das Demandas.

Por meio desses indicadores, o SIESJP pretende identificar, em relação ao item I (insumos, dotações e graus de utilização), os dados sobres as despesas, o pessoal, os recolhimentos e as receitas, a infraestrutura informática e a área física. Em relação ao item II (litigiosidade), pretende calcular o quantitativo de casos novos, a carga de trabalho do magistrado, a taxa de congestionamento da Justiça, a taxa de recorribilidade externa e interna e a taxa de reforma da decisão. Em relação ao item III (acesso à Justiça), pretende avaliar a despesa com assistência judiciária gratuita e o quantitativo de pessoal atendido. Em relação ao item IV (perfil das demandas), pretende levantar a participação governamental nas demandas judiciais.

O sistema de coleta e envio das informações abrange os Tribunais de Justiça dos Estados, os Tribunais Regionais Federais, os Tribunais Regionais do Trabalho e o Tribunal Superior do Trabalho. Os dados são coletados pelos tribunais e enviados semestralmente, no que se refere à litigiosidade, e para as demais variáveis, anualmente, ao SIESJP do $\mathrm{CNJ}^{4}$.

Os responsáveis pelo preenchimento dos dados são indicados pela presidência de cada tribunal. Em sua maioria são integrantes do Núcleo de Estatística e Gestão Estratégica dos tribunais ou assessores da presidência. Os dados são coletados via preenchimento

\footnotetext{
4 Os relatórios do "Justiça em Números", a partir de 2003, podem ser consultados no próprio sítio do CNJ (CONSELHO NACIONAL DE JUSTIÇA, 2013a).
} 
de formulário eletrônico, disponibilizado no sítio do Conselho Nacional de Justiça (cf. CONSELHO NACIONAL DE JUSTIÇA, 2013a). O acesso é feito via sistema de controle de acesso.

Os relatórios, a partir de 2010, apresentaram novidades em sua metodologia: houve novos dados sobre litigiosidade, especificamente para as fases processuais de conhecimento e execução, assim como o quantitativo de processos criminais e de execução fiscal. Houve também, de maneira inovadora, a coleta de dados sobre o grau de implantação do processo eletrônico. Com a finalidade de elucidar as matérias motivadoras dos processos em tramitação, as informações sobre as variáveis foram subdivididas em criminal, não criminal, fiscal e não fiscal.

O sistema "Justiça em Números" é gerido pelo Departamento de Pesquisas Judiciárias do CNJ. Além do sistema, o Departamento possui outros âmbitos de atuação, produzindo pesquisas ou contratando-as, gerindo programas como o "CNJ Acadêmico", o "CNJ Pesquisa" e o "CNJ Ambiental", além de organizar eventos.

Um panorama da produção do Departamento de Pesquisas Judiciárias do CNJ pode ser encontrado em seu site ${ }^{5}$. Destacamos, a seguir, os principais títulos das pesquisas realizadas e disponibilizadas: Novos Diagnósticos do Enfrentamento da Corrupção; Panorama Nacional - A execução de Medidas Socioeducativas de Internação Programa Justiça ao Jovem; 100 Maiores Litigantes (2011); Justiça Infantojuvenil. Situação atual e critérios de aprimoramento. CNJ/IPEA; Estudo Comparado sobre Recursos, Litigiosidade e Produtividade: a prestação jurisdicional no contexto internacional; Relatório sobre o Seminário Justiça em Números - 2010; Panorama do acesso à justiça no Brasil, 2004 a 2009; Demandas repetitivas e a morosidade na justiça cível brasileira; A execução fiscal no Brasil e o impacto no judiciário; 100 Maiores Litigantes (2010); Avaliação do desempenho judicial: desafios, experiências internacionais e perspectivas; Gestão da comunicação nos tribunais; Implantação das tabelas processuais unificadas; Estudo sobre os sistemas de coletas de dados: CNJ; Diagnóstico sobre o funcionamento do Tribunal Regional Federal da $1^{a}$ Região; Relatório sobre a situação dos Conflitos Fundiários Rurais no Brasil em 2008; Principais ações do Conselho Nacional de Justiça - Conflitos Fundiários; $1^{\circ}$ Relatório do

\footnotetext{
5 No sítio "Produção DPJ", do Conselho Nacional de Justiça (cf. CONSELHO NACIONAL DE JUSTIÇA, 2013b), estão disponibilizadas, na íntegra, as pesquisas e relatórios já produzidos pelo Departamento ou em parceria com ele.
}

Programa de Gestão Socioambiental do CNJ; Perfil da fixação de custas judiciais no Brasil e análise comparativa de experiência internacional; Panorama das ações de sustentabilidade do Poder Judiciário; $1^{\circ}$ seminário de Responsabilidade Socioambiental do Poder Judiciário.

Também merece menção os seminários "Justiça em números", realizados anualmente pelo CNJ. No ano de 2010 foi realizada uma edição do seminário e no ano de 2011 foi realizado o IV Seminário ${ }^{6}$.

\section{II.2. O sistema "Justiça Aberta"}

O "Justiça Aberta" é um sistema de coleta de dados que permite a elaboração de relatórios para acompanhar a produtividade dos magistrados e das serventias de maneira sistemática. O foco da coleta são os magistrados. Com essas informações é possível obter uma a visão da produtividade de todo o território nacional, de uma determinada região, estado ou comarca, bem como das atividades de todas as serventias extrajudiciais (cartórios).

Os dados coletados podem ser divididos em três categorias: $(i)$ produtividade mensal $1^{\circ}$ grau: denúncias e queixas, despachos, decisões, sentenças, audiências marcadas, sessão do júri, etc.; (ii) produtividade mensal $2^{\circ}$ grau: acervo, processo administrativos, habeas corpus, agravos de instrumento, distribuição por sorteio, etc.; (iii) recursos humanos: funcionários concursados, terceirizados, requisitados e outros.

A coleta dos dados iniciou-se em setembro de 2007. Os relatórios são disponibilizados na página eletrônica do CNJ, mensalmente. O público-alvo são a Justiça Estadual, Serventias Judiciais de $1^{\circ}$ grau, Serventias Judiciais de $2^{\circ}$ grau e as Serventias Extrajudiciais.

Com relação à responsabilidade pelo preenchimento dos dados, nas Serventias Judiciais os dados são fornecidos pelos Magistrados e suas secretarias. Nas Serventias Extrajudiciais, pelos notários e registradores. Em ambas a coleta dos dados é mensal. O acesso é feito via Sistema de Controle de Acesso na página eletrônica do CNJ.

\section{II.3. A Resolução 88/2009}

A Resolução n. 88, de 8 de setembro de 2009, da Presidência do CNJ, dispõe sobre a jornada de trabalho no âmbito do poder Judiciário, o preenchimento de cargos em comissão e o limite de servidores requisitados. O objetivo geral do sistema de coleta de dados da Resolução n. 88/2009 é conhecer a realidade

\footnotetext{
${ }^{6}$ Cf. Conselho Nacional De Justiça (2013d) para o programa e os slides dos palestrantes do Seminário Justiça em Números de 2010 e 2011.
} 
dos tribunais no que se refere ao preenchimento de cargos em comissão e o quantitativo de servidores requisitados.

São seus objetivos específicos: $(i)$ controlar a atuação administrativa e financeira do Poder Judiciário, bem como zelar pela observância do art. 37 da Carta Constitucional (art. 103-B, $\S 4^{\circ}$, caput e inciso II); (ii) verificar se há distorções quanto à ocupação de cargos em comissão, em descompasso com os ditames do art. 37, incisos IV e V, da Constituição Federal e os parâmetros do art. $5^{\circ}, \S 7^{\circ}$, da Lei n. 11 416/06; (iii) verificar se o funcionamento de vários órgãos de primeira instância do poder Judiciário depende basicamente de servidores requisitados de Prefeituras e diferentes órgãos estaduais e federais.

Os dados coletados são: (i) identificação de cada uma das verbas que compõem a remuneração de cargos efetivos e em comissão existentes no tribunal informante; (ii) identificação do servidor cedido ou requisitado de órgão não pertencente ao poder Judiciário, ocupante ou não de cargo em comissão ou função comissionada no tribunal informante; (iii) relação dos cargos em comissão existentes no tribunal informante, com suas atribuições e dados de ocupação por servidores do quadro, cedidos ou requisitados de outros órgãos do poder Judiciário, cedidos ou requisitados de outros órgãos que não do Judiciário, e sem vínculo com a administração.

A coleta de dados teve início na data de 16 de novembro de 2009. Não há previsão de divulgação dos dados na resolução.

O público-alvo são: Conselho Nacional de Justiça, Justiça Estadual, Justiça Federal, Justiça do Trabalho, Tribunal Superior do Trabalho, Justiça Militar, Justiça Eleitoral, Tribunal Superior Eleitoral e Superior Tribunal de Justiça.

O responsável pelo preenchimento dos dados é a presidência dos tribunais. A periodicidade da coleta é mensal. O acesso ao sistema é feito via Sistema de Controle de Acesso e o preenchimento é realizado por meio do upload de tabelas.

\section{II.4. A resolução 102/2009}

A Resolução n. 102/2009, da Presidência do CNJ, dispõe sobre a regulamentação da publicação de informações alusivas à gestão orçamentária e financeira, aos quadros de pessoal e respectivas estruturas remuneratórias dos tribunais e conselhos.

Seus objetivos são: $(i)$ promover a transparência da gestão e constituir mecanismo de controle social; (ii) padronizar a apresentação das informações, de modo a lhes conferir inteligibilidade e (iii) comparabilidade em benefício da eficácia do controle social sobre os gastos públicos; (iv) permitir a construção de indicadores de eficiência e mecanismos de comparação entre os órgãos jurisdicionados.

Os dados coletados englobam: (i) despesas, repasses e receitas; (ii) acompanhamento da execução orçamentária; (iii) estrutura remuneratória com (a) cargos efetivos, (b) cargos em comissão e funções comissionadas e (c) conselheiros e juízes auxiliares; (iv) quantitativo de cargos efetivos; (v) membros e agentes públicos; $(v i)$ empregados de empresas contratadas em exercício nos órgãos; (vii) servidores e/ou empregados (a) não integrantes do quadro próprio, (b) em exercício no Órgão e (c) sem exercício de cargo em comissão ou função de confiança; (viii) detalhamento da folha de pagamento de pessoal.

O prazo para envio dos arquivos ao $\mathrm{CNJ}$ estendeuse até 31 de março de 2010, ocasião em que deveriam ser encaminhados e publicados os demonstrativos orçamentários consolidados para os exercícios de 2007, 2008 e 2009. A divulgação dos dados está disponível na página eletrônica de cada órgão.

O público-alvo são o Conselho Nacional de Justiça, Conselho da Justiça Federal, Justiça Estadual, Justiça Federal, Justiça do Trabalho, Tribunal Superior do Trabalho, Justiça Militar, Justiça Eleitoral, Tribunal Superior Eleitoral e o Superior Tribunal de Justiça.

O envio dos dados é de responsabilidade do presidente de cada órgão.

Para a periodicidade da coleta temos: $(i)$ despesas, repasses e receitas: mensal; (ii) acompanhamento da execução orçamentária: anual; (iii) estrutura remuneratória (sempre que houver alteração na estrutura remuneratória), composta por (a) cargos efetivos, (b) cargos em comissão e funções comissionadas e (c) conselheiros e juízes auxiliares: trimestral; (iv) quantitativo de cargos efetivos: trimestral; $(v)$ membros e agentes públicos: mensal; (vi) empregados de empresas contratadas em exercício nos órgãos: mensal; (vii) servidores e/ou empregados não integrantes do quadro próprio em exercício no Órgão ou sem exercício de cargo em comissão ou função de confiança: mensal; (viii) detalhamento da folha de pagamento de pessoal: mensal.

$\mathrm{O}$ acesso ao sistema é feito via Sistema de Controle de Acesso e o preenchimento é feito por upload de tabelas no SIAFI-JUD.

\section{II.5. Indicadores do planejamento estratégico do poder Judiciário}

A Resolução n. 70, de 18 de março de 2009, da Presidência do CNJ, dispôs sobre o Planejamento e a 
Gestão Estratégica no âmbito do Poder Judiciário. Os indicadores de desempenho são utilizados na mensuração dos resultados do Planejamento Estratégico.

Os dados coletados são 43 indicadores em eixos temáticos distintos. $\mathrm{O}$ início da coleta teve previsão para o final de 2010. O público-alvo é: Justiça Estadual, Justiça Federal, Justiça do Trabalho, Justiça Militar, Justiça Eleitoral, Tribunal Superior do Trabalho, Tribunal Superior Eleitoral e Superior Tribunal de Justiça.

O responsável pelo preenchimento dos dados é o Núcleo de Gestão Estratégica dos tribunais ou unidade análoga. A coleta possui diferentes periodicidades. $\mathrm{O}$ acesso ao sistema é feito pelo sistema de gestão de indicadores centralizado e disponível a todos os tribunais, que possibilitará a captura automática dos dados pelos tribunais superiores, conselhos e CNJ.

\section{II.6. O projeto "Supremo em Números"}

A Fundação Getúlio Vargas, por meio da Escola de Direito do Rio de Janeiro e com o apoio da Escola de Matemática Aplicada, lançou recentemente o projeto "Supremo em Números". O objetivo do projeto é realizar análises quantitativas sobre a atuação do Supremo Tribunal Federal, fundamentando, quantitativa e estatisticamente, discussões sobre a natureza, a função e o impacto da atuação do STF na sociedade brasileira.

O projeto pretende trabalhar a partir do banco de dados do STF, composto por mais de 1,2 milhão de processos - sendo 1132850 já julgados e 89252 ainda ativos, quase 14 milhões de andamentos, 240 mil advogados, um milhão de partes e mais de 370 mil decisões, desde 1988 até os dias de hoje.

$\mathrm{O}$ primeiro relatório do projeto já foi produzido e disponibilizado ao público (SUPREMO EM NÚMEROS, 2011).

A metodologia do projeto consiste, em oposição ao modelo de análise qualitativa, mais difundido, realizar uma análise quantitativa e estatística sobre a natureza, a função e o impacto da atuação do STF na democracia brasileira. Dado que os tribunais superiores brasileiros julgam centenas de milhares de processos ao ano, um quantitativo muito superior aos tribunais de outras grandes democracias ocidentais, o objeto de estudo do projeto será os grandes bancos de dados do poder Judiciário brasileiro. Como geralmente esses bancos de dados não estão disponíveis ou muitas vezes são incompletos ou possuem muitas informações redundantes, incompletas ou inconsistentes, o projeto também pretende desenvolver e empregar novas técnicas computacionais que permitam a sua análise.
III. RUMO À COLETAAUTOMÁTICA DE DADOS: O SISTEMA DE GESTÃO DE TABELAS PROCESSUAIS UNIFICADAS

O CNJ, por meio da criação do Sistema de Gestão de Tabelas Processuais Unificadas, deu os primeiros passos para a coleta automática de dados. Atualmente, na maioria dos sistemas, o CNJ requisita as informações aos tribunais e as recebe na forma de planilhas. Um dos inconvenientes de alguns sistemas é que a coleta da informação ainda é manual. Uma parcela significativa do tempo administrativo dos servidores e funcionários dos cartórios e dos tribunais é consumido para a feitura e finalização dos relatórios. Dado que esse tempo diminui o tempo dedicado à atividade fim, que é a gestão do sistema processual, cria-se, por parte dos servidores, uma rejeição e mesmo uma imagem negativa em relação ao significado da tarefa de coleta de informações e de preenchimento de planilhas.

Algumas técnicas computacionais permitem a coleta automática da informação e a geração automática de relatórios. Com essa meta de caráter amplo, o CNJ elaborou o Sistema de Gestão de Tabelas Processuais Unificadas.

Um relato dos objetivos, etapas e estado atual do Sistema de Gestão de Tabelas Processuais Unificadas pode ser encontrado no documento de sua apresentação, elaborado pelo Juiz Auxiliar da Presidência do CNJ, Marivaldo D. de Araújo, por ocasião do III Seminário Justiça em Números, realizado em 23 e 24 de setembro de 2010 em Brasília (ARAÚJO, 2010). Nos parágrafos seguintes, transcrevemos algumas informações importantes do seu documento.

As tabelas foram instituídas pela Resolução $n^{\circ} 46$, da Presidência do CNJ, de dezembro de 2007. Houve uma previsão inicial de implantação para o ano de 2009. O sistema foi possível através de acordos de cooperação entre o CNJ e os tribunais.

O sistema padronizou as informações processuais através de três tabelas: $(i)$ uma tabela de classes, para a padronização, em todo o território nacional, da classificação do procedimento administrativo ou judicial a ser utilizado nos diversos graus de jurisdição; (ii) uma tabela de assuntos, que padroniza nacionalmente a classificação das matérias e temas abordados nos processos; (iii) por fim, uma tabela de movimentação, que padroniza nacionalmente o registro dos andamentos e atos processuais.

Segundo o Juiz Marivaldo D. de Araújo, com as tabelas padronizadas, o sistema procura alcançar os seguintes objetivos: "possibilitar uma maior controle dos processos, em razão da padronização; extrair dados estatísticos necessários aos Tribunais e CNJ de forma 
automatizada e simplificada; permitir à Secretaria e ao magistrado um maior conhecimento do acervo, tanto em termos quantitativos quanto qualitativos (assuntos mais frequentes); melhorar a gestão de pauta; incrementar o Processo Virtual; racionalizar o fluxo do processo (encadeamento dos atos processuais); melhorar o controle de prevenção e distribuição processual por competências em razão da matéria; possibilitar o aproveitamento, pelas instâncias superiores, das informações processuais dos sistemas de $1^{\circ}$ e $2^{\circ}$ graus; identificar o tempo médio de duração das fases do processo ("gargalos"); e, por fim, identificar os assuntos mais freqüentes para atuação preventiva" (ARAÚJO, 2010, s.p.).

As tabelas são geridas por um sistema eletrônico de gestão e por um comitê gestor nacional. A gestão é compartilhada pelos diferentes ramos do poder Judiciário e há também um grupo gestor em cada tribunal, que administra as alterações ou inclusões das tabelas. O conteúdo das tabelas está disponível na internet, via consulta pública (CONSELHO NACIONAL DE JUSTIÇA, 2013c). O sistema possibilita a consulta por parte do nome, pelo glossário ou pelo código da classe, assunto ou movimento.

Há várias vantagens na utilização de um sistema parametrizado: primeira, ele evita divergências de interpretações pelos órgãos julgadores; segunda, e que talvez seja a principal delas, a coleta das informações pelos sistemas dos tribunais passa a ser automatizada. Logicamente, o tempo dedicado ao preenchimento manual das planilhas e também à consolidação dos números finais das planilhas é economizado.

No modo como foi construído o Sistema de Gestão de Tabelas Processuais Unificadas, fica evidenciada a preocupação com o tempo de duração do processo. $\mathrm{O}$ sistema pretende coletar esta informação e identificar em quais etapas dos movimentos processuais o andamento é mais lento. Em outros termos, trata-se de identificar os "gargalos" do sistema processual e onde há o congestionamento. A solução para o congestionamento, do ponto de vista do gerenciamento processual, pode ser pensada a partir da correlação entre ele e a fase processual no qual ocorre. As tabelas processuais unificadas também indicam quais os movimentos processuais relevantes para a apuração de cada variável do "Justiça em Números", e eventualmente o momento da sua ocorrência.

O sistema também permitirá a geração e a exportação de relatórios, permitindo às varas $\mathrm{e}$ gabinetes uma gestão mais eficiente dos processos, a geração automática de estatísticas, o aumento da qualidade da informação prestada às partes e aos advogados, minimizando o uso do atendimento no balcão e, por fim, tornando a base de dados mais próxima da realidade.

\section{ALGUMAS BASES METODOLÓGICAS PARAA Q-JUSTIÇA NO BRASIL}

Por meio de um breve exame do estado da Q-Justiça no Brasil, é possível concluir que o sistema estatístico do poder judicial brasileiro está em seus passos iniciais, em vias de completar uma década de existência. Para uma Q-Justiça efetivamente transparente, é preciso que os bancos de dados do poder Judiciário sejam amplamente publicados, a fim de permitir que os pesquisadores das mais diversas áreas, como os juristas, os sociólogos e os cientistas políticos possam submeter a massa de dados a análises comparativas, e que as conclusões possam ser livremente estabelecidas.

Tanto o sítio do CNJ como o sítio do STF disponibilizam atualmente os dados no formato de relatórios, nos quais as informações já foram registradas e depuradas pela equipe interna do órgão ${ }^{7}$.

Para uma Q-Justiça efetivamente aberta e democrática, algumas recomendações de ordem metodológica podem ser elencadas: (i) quanto à disponibilização dos dados: é preciso haver uma cultura de transparência e de livre disponibilização dos dados.

A recente Lei de Acesso à Informação (Lei n. 12 527, de 18 de novembro de 2011), em vigor desde maio de 2012, já significa um importante avanço nesse sentido. O sistema judicial não pode ser um sistema fechado, deve ser um sistema aberto à sociedade e principalmente à consulta pública e à pesquisa científica. Indiretamente, o grande empecilho para a efetivação da transparência consiste na interface técnica, ou seja, a questão, em termos atuais, pode ser assim colocada: como a sociedade civil pode ter acesso ao sistema judicial utilizando as modernas tecnologias de informação? No sentido inverso, como podem os tribunais fazerem uso das tecnologias de informação para fornecerem à sociedade as suas informações relevantes? Nesse sentido, o próximo item é de suma importância.

(ii) Os dados fornecidos pelo sistema judicial devem estar padronizados em formatos usuais de banco de dados.

\footnotetext{
7 Entre o tempo de redação e a finalização do presente artigo, o CNJ disponibilizou, através da

Portaria n. 216, de 19 de dezembro de 2012, toda a base de dados que embasa o Relatório "Justiça em Números", a partir do ano de 2009, para livre consulta no sítio http://www. cnj.jus.br/programas-de-a-a-z/eficiencia-modernizacao-etransparencia/pj-justica-em-numeros/2013-01-04-19-13-21.
} 
Os tribunais deveriam divulgar informações em formatos abertos, acessíveis e legíveis por sistemas computacionais. Infelizmente, a grande maioria dos relatórios é divulgada no formato PDF, que geralmente é um documento fechado e de difícil edição, pois necessita ser convertido em outro formato. Seria recomendável que os formatos dos relatórios fossem disponibilizados em extensões usuais de banco de dados, como XML, JSON ou CSV. Uma grande parte do tempo, para o cientista social que se debruça sobre os dados dos tribunais, é gasto na coleta manual da informação da pesquisa nas planilhas, quando a mesma poderia ser manejada de modo automático por um programa de computador.

(iii) Seria recomendável uma padronização no formato da oferta dos dados para todo o poder Judiciário.

Para que a informação seja analisada por um programa de computador, qualquer caractere é significativamente diferente do outro. No formato de um número em um relatório, por exemplo, o uso da vírgula é bem diferente do uso do ponto. Em certos casos, utiliza-se para o mesmo número diferentes formatos, como 3,99 e 3.99. Sem a intervenção humana, um computador não tem como interpretar os dois formatos como sendo iguais. A mesma observação vale para a contagem de espaços e para a utilização de letras minúsculas e maiúsculas.

Uma vez disponibilizada a massa de dados, a vantagem da utilização dos programas de computador para analisá-los é que eles permitem a criação de aplicativos e de visualizações sobre os dados. Isso não quer dizer que a análise é automática: é preciso que o pesquisador selecione previamente quais são os dados relevantes para determinada análise.

Atualmente, a Ciência da Computação já desenvolveu técnicas automatizadas de análise de dados. Nos próximos itens, abordamos duas técnicas atuais, a Mineração de Dados e a Computação em Nuvem, que certamente podem produzir os próximos desenvolvimentos e uma nova geração de Justiça quantitativa.

\section{PRÓXIMOS AVANÇOS EM Q-JUSTIÇA}

\section{VI.1. Mineração de dados (data mining)}

Uma vez que a massa de dados do sistema judicial seja disponibilizada, algo que projetamos para um futuro próximo, é preciso que se possa extrair informações qualitativas sobre os dados, e principalmente que se possa obter um conhecimento das correlações existentes entre eles. Usualmente, os mecanismos de análise dos dados usados na pesquisa empírica em Direito no Brasil é intuitiva e baseada na experiência e sensibilidade do pesquisador. Porém, como é amplamente conhecido, o aumento do número de litígios tende a crescer exponencialmente nos próximos anos por vários fatores, como o aumento de renda da população brasileira e a ampliação do rol dos direitos. Conseqüentemente, teremos um aumento do número de causas judiciais e, ao mesmo tempo, um aumento da complexidade do sistema judicial. Certamente, a experiência e a sensibilidade do pesquisador na pesquisa jurídica empírica é e não deixará de ser importante, porém, para o desenvolvimento de análises mais refinadas e que lidem com uma quantidade massiva de dados, a pesquisa manual encontra seus limites, em algum casos a sua impossibilidade, e o pesquisador precisará utilizar técnicas avançadas para a análise computacional dos dados. É nesse contexto que a mineração de dados pode ser utilizada na pesquisa jurídica empírica.

A mineração de dados é um ramo da Computação que teve início por volta de 1980. Ela surgiu primeiramente como ferramenta para a análise dos dados de grandes empresas e organizações, que no curso da sua atividade, acumulavam uma quantidade massiva de informação. A análise dos bancos de dados poderia fornecer informações que não estavam aparentes e que, uma vez conhecidas, poderiam otimizar e aumentar a performance da organização.

Atualmente, com o aumento do trânsito de dados dos computadores para os celulares e dispositivos intermediários, como tablets, a mineração de dados é cada vez mais empregada como técnica de análise automática de informações e geração de conhecimento; como o próprio termo designa, trata-se de minerar os dados.

A CNJ, nos recentes relatórios mencionados no início deste artigo, já produziu um conhecimento gerado a partir das estatísticas judiciais. Um dado importante foi o levantamento do custo unitário do processo em cada um dos sistemas estaduais de justiça da federação brasileira. Além desses, muitos outros dados podem ser extraídos por meio das variadas técnicas de mineração de dados.

Em termos conceituais, a mineração de dados consiste no desenvolvimento de um algoritmo que define regras de associação, descoberta de padrões sequenciais, classificação e análise de objetos. Para que a Mineração de Dados possa ser empregada com mais êxito, é preciso que os bancos de dados passem por um processo preparatório e mais amplo, que consiste na chamada Descoberta de Conhecimento em Banco de Dados, ou em inglês Knowledge Discovery in Databases (KDD), com as seguintes etapas, de acordo com Sandra de Amo: "1 - Limpeza dos dados: 
etapa onde são eliminados ruídos e dados inconsistentes. 2 - Integração dos dados: etapa onde diferentes fontes de dados podem ser combinadas, produzindo um único repositório de dados. 3 - Seleção: etapa onde são selecionados os atributos que interessam ao usuário. Por exemplo, o usuário pode decidir que informações como endereço e telefone não são relevantes para decidir se um cliente é um bom comprador ou não. 4 - Transformação dos dados: etapa onde os dados são transformados num formato apropriado para aplicação de algoritmos de mineração (por exemplo, através de operações de agregação). 5 - Mineração: etapa essencial do processo consistindo na aplicação de técnicas inteligentes a fim de se extrair os padrões de interesse. 6 - Avaliação ou Pósprocessamento: etapa onde são identificados os padrões interessantes de acordo com algum critério do usuário. 7 - Visualização dos Resultados: etapa onde são utilizadas técnicas de representação de conhecimento a fim de apresentar ao usuário o conhecimento minerado" (AMO, 2004, p. 2-3).

Uma vez que os dados foram filtrados e unidos em um banco de dados, é possível aplicar o algoritmo de mineração de dados para análises automatizadas. É importante distinguir entre tarefas de mineração e técnicas de mineração. A tarefa consiste no estabelecimento das regularidades ou padrões que temos interesse em encontrar ou, pelo contrário, que esperamos não encontrar. As técnicas consistem na especificação dos métodos que nos permitem a descoberta dos padrões que nos interessam.

A mineração de dados pode utilizar técnicas estatísticas e técnicas de aprendizado de máquina. De modo resumido, as principais tarefas de mineração são: (i) análise de regras de associação. Uma regra de associação é um padrão da forma $X{ }^{\circledR} Y$, onde X e Y são conjuntos de valores ou comportamentos quaisquer. Por exemplo, um cliente que compra uma escova de dente (X) também compra uma pasta de dente (Y). Uma parte que demanda indenização por danos materiais, em geral, também demanda indenização por danos morais. As regras de associação são importantes para a determinação de correlações. (ii) Análise de padrões sequenciais. Um padrão sequencial é uma expressão que representa uma seqüência cronológica de eventos. Descobrir qual a ordem cronológica de certos eventos pode ser de suma importância. (iii) Classificação e predição. A classificação consiste na determinação de uma classe ou categoria de objetos. Essa classe, corretamente classificada, é utilizada para predizer um conjunto de objetos que ainda não foram classificados. Há técnicas que permitem o treinamento do sistema para que ele faça uma predição, como as redes neurais e as árvores de decisão. (iv) Análise de clusters (agrupamentos). A análise de clusters é ligeiramente diferente da classificação e da predição. Nestas, os dados de treinamento estão devidamente classificados e as etiquetas das classes são conhecidas. Já a análise de clusters trabalha sobre dados nos quais as etiquetas das classes não estão definidas; são os agrupamentos de objetos que definem uma classe. (v) Análise de outliers. Em um banco de dados, é possível que o interesse de análise esteja não sobre a regra ou padrão geral, mas sobre as exceções (outliers). Por exemplo, na detecção de fraudes em cartões de crédito, a análise é feita para a descoberta de padrões de gasto fora do habitual.

Com essas técnicas, um campo novo de análise está aberto para a pesquisa empírica na área jurídica. Um exemplo recente de aplicações de técnicas de mineração de dados pode ser encontrado no projeto "O Supremo em Números"8. O próprio CNJ, no Comitê Nacional de Gestão da Tecnologia da Informação do Poder Judiciário, possui um sistema interno de business intelligence, ou seja, de emprego de técnicas análogas à Mineração de Dados.

\section{IV.2. Computação "em nuvem” (cloud computing)}

Muitos analistas de tecnologia prevêem que a próxima geração dos computadores e da internet seja baseada na "nuvem" (cloud). O termo computação em nuvem (em inglês, cloud computing) refere-se à centralização de certas funções, como o armazenamento, a memória, o processamento e o software em servidores centrais, que se comunicam

\footnotetext{
8 Os pesquisadores Flávio Codeço Coelho, Renato Rocha Souza e Pablo de Camargo Cerdeira desenvolveram duas aplicações sobre a base de dados de processos do STF. Na primeira aplicação, com o trabalho "Talk Information Mining and Visualization of a Large Volume of Legal Texts" (COELHO, SOUZA \& CAMARGO, 2011) eles desenvolveram uma animação que "mostra os primeiros testes de plotagem do ordenamento jurídico brasileiro segundo o Supremo. Ele relaciona as leis citadas nas mais de 1,2 milhão de decisões analisadas. Quando duas leis são citadas conjuntamente na mesma decisão elas formam um link entre si, e a cada nova decisão em que aparecem conjuntamente esse link é fortalecido. Com isso conseguimos visualizar como os ministros do STF as associam, vendo isso no espaço" (idem). A segunda aplicação utilizou uma técnica de clusters com base em diversas variáveis: "os galhos principais são os estados da federação, as primeiras ramificações são os tipos de decisão (monocrática, presidência, pleno etc.), as segundas ramificações representam as classes processuais (agravos de intrumento, ADIs etc.) e as folhas (os círculos ao final) representam a quantidade de decisões proferidas. Com isso torna-se possível visualizar quais os estados que mais crescem, a cada período, em cada tipo de decisão, em cada classe processual. Essa grande quantidade de informações é quase impossível de ser percebida em visualizações tradicionais de gráficos" (CERDEIRA, 2011).
} 
com o usuário por meio da internet.

Tradicionalmente, o computador do usuário possui um software instalado em seu hardware. Com a computação em nuvem, grande parte do software, do processamento e da memória do computador do usuário não é mais necessário, pois os mesmos estão centralizados no servidor ou na nuvem. A computação em nuvem somente é possível devido ao aumento gradativo e intensivo da velocidade de conexão da internet, bem como do poder de processamento dos servidores centrais. Deste modo, os aparelhos dos usuários, como tablets e celulares, cumprem todas as funções de um computador tradicional, porém com uma construção física muito mais simplificada e igualmente com um software menos pesado, que consome menos memória e exige menos processamento. Com a computação em nuvem, não é mais necessário instalar um software no computador do usuário para utilizá-lo, ele pode ser utilizado acessando "a nuvem".

Gradativamente, as grandes empresas de tecnologia como Google, IBM e Microsoft estão oferecendo seus serviços baseados em computação em nuvem. Talvez o mais conhecido destes sistemas seja o popular Google Docs, no qual a plataforma Office funciona no ambiente web. Outros serviços fornecidos pelo Google, como o YouTube, também disponibilizam ferramentas que antes somente existiam em software, como conversão de formatos de vídeo, seu processamento etc. Atualmente o Google desenvolve o sistema operacional para internet chamada Google Chrome OS. Os dispositivos ChromeBooks possuem suas aplicações e arquivos salvos na nuvem e funcionam com um disco rígido de apenas 16 Gigabytes $(\mathrm{Gb})$. A Apple também desenvolve atualmente seu sistema de computação em nuvem, o iCloud, e a IBM o Smart Business.

O serviço de computação em nuvem pode ter diferentes níveis de acesso, desde nuvem públicas até nuvens mistas e nuvens privadas.

Um dos grandes entraves à implantação do processo eletrônico em todo o sistema judicial no Brasil é o problema da interoperabilidade. Nos últimos anos, praticamente cada ramo do poder Judiciário criou e implantou um sistema próprio de processo eletrônico, e a grande dificuldade para os usuários finais, os advogados, é terem de lidar com inúmeros sistemas, cada qual com suas peculiaridades, e que não se comunicam entre si.

A computação em nuvem pode ser uma das soluções para o problema da interoperabilidade dos sistemas processuais informatizados. Com sua adoção, não haveria problemas de incompatibilidade, por exemplo, entre os sistemas dos tribunais e os sistemas das varas e das serventias. Praticamente, o software e o hardware do computador pessoal do usuário tornamse secundários; a sua função passa a ser apenas a de prover acesso à internet e ao sistema. Outra vantagem diz respeito à atualização do software, o qual pode ser realizado de maneira automática e sem intervenção do usuário. Há também uma diminuição de custos, pois os computadores pessoais não necessitarão de manutenção individual de software, nem o usuário precisará necessariamente pagar uma licença de uso do sistema operacional.

Do ponto de vista da Q-Justiça, as vantagens são inúmeras. Um Tribunal poderá ser totalmente interligado, e o sistema de coleta de dados passa a ser automático, pois não haverá divisões entre os sistemas processuais informatizados. Alguns pesquisadores em métrica judicial dos Estados Unidos cunharam o termo "Smart Courts" para os tribunais que empregarão as técnicas de computação em nuvem (KEILITZ, 2010). Além da coleta de dados ser automática, os tribunais poderão contar com aplicativos que podem fornecer gráficos e tabelas dinâmicas, atualizadas em tempo real, para o diagnóstico e medição do seu funcionamento ${ }^{9}$.

Em todo esse panorama, necessariamente surge a questão do controle das informações. Atualmente, as grandes empresas como Google e Facebook enfrentam processos judiciais visando questionar o uso que elas fazem dos dados pessoais dos seus usuários. Não há como negar que as relações de poder e de hierarquia permeiam as decisões sobre a adoção dessas novas tecnologias e sistemas e o quanto um sistema de um órgão deve (ou não) ficar subordinado a outro.

\section{CONCLUSÃO}

A finalidade do presente trabalho foi, primeiramente, a de expor para um público variado de pesquisadores, tanto do Direito como das Ciências Sociais em geral, o atual sistema de coleta de dados e elaboração de índices do poder Judiciário no Brasil. Gradativamente, com o atual sistema e com o estabelecimento de uma série histórica cada vez maior de relatórios temáticos ou anuais, os bancos de dados judiciais tendem a crescer e permitirão uma análise mais refinada do funcionamento do sistema judicial no Brasil. O atual sistema também está em permanente processo de modernização, rumo à coleta automática dos dados e à padronização das informações relativas aos processos. Também, em um futuro próximo, teremos bancos de dados judiciais com informações mais consistentes. E, finalmente, com a mineração de dados e com a

\footnotetext{
${ }^{9}$ Um exemplo de gráficos dinâmicos é o sistema utilizado pela Corte Judicial do estado americano de Utah, o Utah Courts Performance Measures (UTAH STATE COURTS, 2013).
} 
computação em nuvem, que podem ou não ser adotadas nos sistemas de Justiça Eletrônica no Brasil, uma nova perspectiva de Q-Justiça pode ser ofertada, com uma produção massiva de dados que, contudo, devem sempre ser submetidos a um juízo rigoroso sobre a viabilidade da sua divulgação, e conseqüentemente, sobre qual uso os atores envolvidos nos sistema judicial brasileiro dele farão.

Cesar Antonio Serbena (cserbena@uol.com.br) é Doutor em Direito pela Universidade Federal do Paraná (UFPR) e Professor da Faculdade de Direito da mesma universidade.

\section{REFERÊNCIAS BIBLIOGRÁFICAS}

AMO, S. 2004. Técnicas de mineração de dados. Trabalho apresentado no XXIV Congresso da Sociedade Brasileira de Computação, realizado em Salvador, de 31 de julho a 6 de agosto. Digit. Disponível em www.lsi.ufu.br/documentos/publicacoes/ ano/2004/JAI-cap5.pdf. Acesso em: 11.abr.2013.

ARAÚJO, M. D. 2010. A importância das tabelas processuais unificadas para coleta de dados. Disponível em: http://www.cnj.jus.br/images/pesquisas-judiciarias/iii-seminario-justica-em-numeros/ apre_marivaldo_araujo_jn_2010.pdf. Acesso em: 11.abr.2013.

CERDEIRA, P. 2011. Integração entre Direito e Matemática é promissora. Supremo em números, 19.out. Disponível em: http://www.supremo emnumeros.com.br/2011/integracao-entre-direitoe-matematica-e-promissora/. Acesso em: 11.abr.2013.

COELHO, F.; SOUZA, R. R. \& CERDEIRA, P. C. 2011. Talk Information Mining and Visualization of a Large Volume of Legal Texts. Trabalho apresentado no EuroSciPy - Annual European Conference for Scientists using Python, realizado em Paris, de 25 a 28 de agosto. Digit.

KEILITZ, I. 2010. Smart Courts: Performance dashboards and business intelligence. In: FLANGO, C.; MCDOWELL, A.; CAMPBELL, C. \& KAUDER, N. (eds.). Future Trends in State Courts 2010. Williamsburg: National Center for State Courts.

\section{OUTRAS FONTES}

CONSELHO NACIONAL DE JUSTIÇA. 2010. Estudos sobre os sistemas de coleta de dados: CNJ / Conselho Nacional de Justiça. Série "CNJ Acadêmico", n. 4. Brasília: Conselho Nacional de Justiça.

2013a. Justiça em números. Disponível em: https:/ /estatistica.cnj.jus.br. Acesso em: 11.abr.2013.

. 2013b. Produção DPJ. Disponível em: http:// www.cnj.jus.br/pesquisas-judiciarias/2011-08-1019-36-05. Acesso em: 11.abr.2013.

.2013c. Sistema de Gestão de Tabelas Processuais Unificadas. Disponível em: http:// www.cnj.jus.br/sgt/versoes.php. Acesso em: 11.abr.2013.

. 2013d. III Seminário Nacional em Números. Disponível em: http://www.cnj.jus.br/pesquisasjudiciarias/eventos/iii-seminario-justica-emnumeros. Também disponível em: http:// www.cnj.jus.br/component/content/ article?id=15841. Acesso em: 11.abr.2013.
EUROPEAN COMMISSION FOR THE EFFICIENCY OF JUSTICE. 2010. European Judicial Systems - Edition 2010 (data 2008): Efficiency and quality of justice. Strasbourg: Council of Europe.

NATIONAL CENTER FOR STATE COURTS. 2010. Examining the Work of the Courts: An analisys of state court caseloads, 2010. Disponível em: http:// www.courtstatistics.org/Other-Pages/Examiningthe-Work-of-State-Courts.aspx. Acesso em: 11.abr.2013.

SUPREMO EM NÚMEROS. 2011. I Relatório-abril/ 2011 - O Múltiplo Supremo. Disponível em: http:/ /www.supremoemnumeros.com.br/i-relatorioabril2011-o-multiplo-supremo/. Acesso em: 11.abr.2013.

UTAH STATE COURTS. 2013. Utah Courts Performance Measures. Disponível em: http:// www.utcourts.gov/courtools/. Acesso em: 11.abr.2013. 